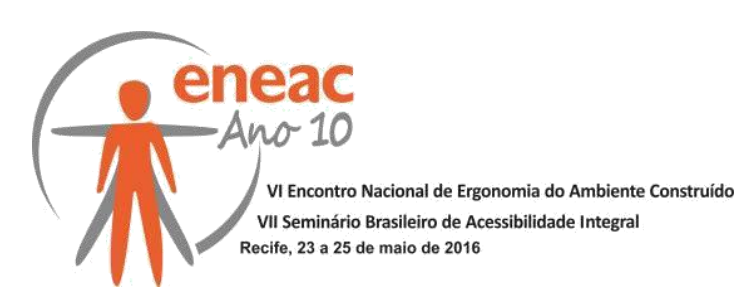

\title{
O DEFICIENTE VISUAL E O ESPAÇO URBANO - COMPREENDENDO OS ATRIBUTOS DE APROPRIAÇÃO DO AMBIENTE
}

\author{
BAPTISTA, Mariana Bertani (1); \\ BERNARDI, Núbia (2) \\ (1) Universidade Estadual de Campinas, Mestranda \\ e-mail: mariberbap@yahoo.com.br \\ (2) Universidade Estadual de Campinas, Doutora \\ e-mail : nubiab@fec.unicamp.br
}

\begin{abstract}
RESUMO
Este artigo apresenta uma discussão sobre a compreensão e a apropriação do espaço urbano por pessoas com deficiência visual, quais os instrumentos utilizados e considerados importantes para sua mobilidade na cidade. A metodologia utilizou o mapeamento visual e o mapeamento sensorial. Aliado à pesquisa bibliográfica sobre tecnologias assistivas, foi realizado um estudo de caso onde foram obtidas informações valiosas ao aprendizado da mobilidade. Com esta experiência foi possível avaliar como os instrumentos de apoio e os estímulos gerados pelo ambiente são apreendidos pelos usuários contribuindo para sua inclusão sócio-espacial.
\end{abstract}

Palavras-chave: Desenho Universal; Orientação espacial; Deficientes Visuais.

\begin{abstract}
This article presents a discussion on understanding and appropriation of urban space for people with visual impairments, which instruments are used and considered important for their mobility in the city. The methodology used were the visual mapping and sensory mapping. Combined with bibliographic research on assistive technologies, it conducted a case study where were obtained valuable information to learning mobility. With this experience it was possible to assess the support tools and incentives generated by the environment are seized by users contributing to its social and spatial inclusion.
\end{abstract}

Keywords: Universal Design; Spatial orientation; Visually impaired.

\section{INTRODUÇÃO}

Foi no século XVIII que surgiram as primeiras preocupações dos profissionais da saúde em classificar as doenças. No entanto, apenas em 1948, durante a VI Revisão da Classificação Internacional de Doenças - CID-6, é que são feitas referências à doenças que exigiriam atendimento além dos cuidados médicos, como deficiências de nascença e adquiridas, principalmente porque após a Segunda Grande Guerra houve um grande número de 


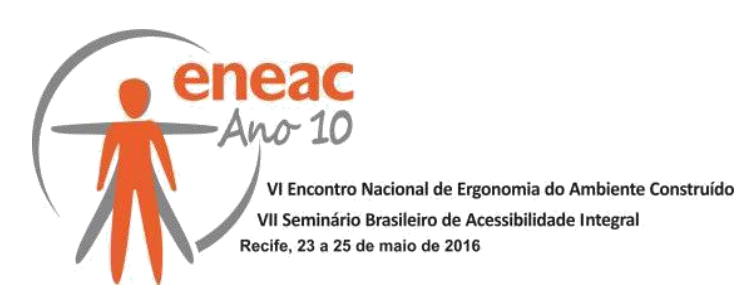

soldados retornando para suas casas com membros amputados e diversas outras sequelas, o que aguçou ainda mais a demanda por cuidados necessários para a reinserção destes indivíduos na sociedade.

No Brasil, somente em 1999, com o Decreto 3.298 é que foi definida como "pessoa portadora de deficiência é aquela que apresenta, em caráter permanente, perda ou anormalidade de uma estrutura de função psicológica, fisiológica ou anatômica que gera incapacidade para o desempenho de atividade, dentro do padrão considerado normal". Segundo os Dados do Censo Demográfico de 2010, o Brasil possui 45 milhões de habitantes que possuem alguma deficiência, dos quais cerca de 35 milhões apresentam desde alguma deficiência visual até a total impossibilidade de enxergar (IBGE, 2010).

É neste contexto que o conceito do Desenho Universal torna-se extremamente importante para a produção e adequação do espaço urbano para estes habitantes que apresentam necessidades diferenciadas e habilidades outras para se locomover. A partir dos pressupostos de prover a equiparação do uso, a flexibilidade no uso (que deve ser simples e intuitivo), assegurar a percepção de informação e minimizar os riscos de acidentes, oferecendo um espaço para uso e interação que exija pouco esforço físico, o Desenho Universal é uma forma de conceber tais ambientes, produtos e meios de comunicação de modo a serem utilizados por todas as pessoas, com deficiência ou não, durante o maior tempo possível sem que haja a necessidade de adaptação ao meio ou ao objeto. O objetivo do Desenho Universal é beneficiar simultaneamente todas as idades e todas as capacidades. (STORY, 2001).

Este artigo apresenta os resultados obtidos na pesquisa de iniciação cientifica intitulada 'Mobilidade no espaço urbano: compreensão dos atributos do ambiente através da percepção de indivíduos com deficiência visual', realizada de agosto de 2012 a julho de 2013, com orientação da Prof. Dra. Núbia Bernardi, e com apoio da PIBIC - CNPq.

\section{REVISÃO BIBLIOGRÁFICA E PESQUISA DE TECNOLOGIAS EM ORIENTAÇÃO E MOBILIDADE:}

Para a primeira etapa da pesquisa foram levantados e estudados cerca de 50 textos acadêmicos, de autores brasileiros e internacionais, dentre artigos, cartilhas, workshops e teses, sobre a relação entre a deficiência visual e os demais assuntos da presente pesquisa: o desenho universal, a mobilidade urbana, a orientação espacial e as tecnologias assistivas existentes e em desenvolvimento.

O início da pesquisa bibliográfica foi norteado principalmente pelo termo acessibilidade. A partir dele foram pesquisados outros termos já previstos, como mobilidade, orientação espacial e o conceito de wayfinding, bem como os termos que se descobriram importantes como usabilidade e integração, todos os termos voltados à locomoção do deficiente visual.

Também mereceram atenção especial as tecnologias assistivas, pois foram quesitos fundamentais para a pesquisa de campo realizada na parte final do trabalho, onde houve 0 estudo e a familiarização com os equipamentos de ensino da mobilidade e orientação espacial que são utilizadas ou que estão em processo de pesquisa e desenvolvimento, tanto no Brasil como no exterior. Os instrumentos estudados compreenderam desde o mapeamento visual, passando pelo plano da cartografia tátil e finalizando com ações e reações do próprio corpo do deficiente visual, e de como ele faz uso desses instrumentos, do aprendizado ao uso prático.

Nos resultados apresentados nesta pesquisa, ficou clara a utilização do próprio corpo do deficiente visual como sendo o reconhecedor maior do ambiente construído. Como a grande maioria das tecnologias assistivas ainda não é financeiramente acessível para a maior parte 


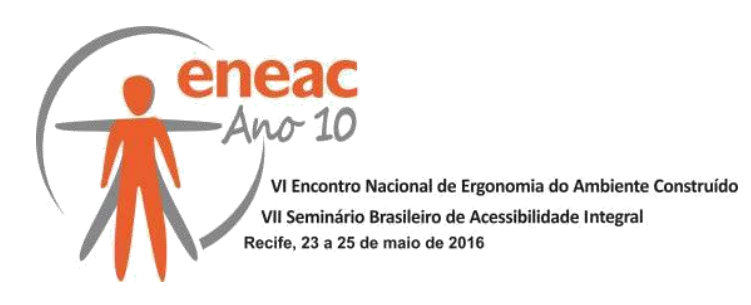

da população brasileira, é através do corpo que o deficiente visual aprende a reconhecer desde os ambientes confortáveis até os lugares que podem apresentar algum risco à sua integridade física.

Com foco na mobilidade de um deficiente visual, foram elencados dois tipos de mapeamento relevantes ao ganho de independência destes indivíduos. São eles o mapeamento visual e o mapeamento sensorial. A pesquisa sobre técnicas e tecnologias assistivas foi baseada também nestes tipos de mapeamento.

Rheingantz (2009, p.50) definiu o Mapeamento Visual como uma ferramenta de pesquisa que contribui para delinear os atributos utilizados na avaliação da identidade do local, resultado da interação homem e lugar, e principal responsável pelo sentimento de integração e pertencimento. E Ventorini (2009 in Ulbricht et al., 2011, p.6) descreveu o Mapa Sensorial como sendo as formas de organização do espaço marcadas pelas experiências pessoais de cada deficiente visual. Por esta razão eles organizam mentalmente os espaços através de rotas ou ambientes que representem alguma vivência para eles (Santos, 1999).

Diversas são as informações necessárias para o desenvolvimento de tais mapeamentos por cada um dos indivíduos, apreendidas de maneiras diferentes. Dischinger et al (2008) afirma que tanto a Informação Arquitetônica quanto a Informação do Objeto podem ser complementadas por outras modalidades de informação, as quais chamamos de Informações Adicionais. Essas podem ser de natureza gráfica, sonora, verbal ou tátil. No caso de espaços de alta complexidade, como os campi universitários e edifícios de múltiplos andares, a informação adicional é sempre necessária.

A partir deste levantamento bibliográfico e sobre as tecnologias e instrumentos focados na mobilidade de um deficiente visual, foi possível inferir que a acessibilidade gera, ou ao menos facilita, a mobilidade de qualquer cidadão; e que as estratégias de wayfinding, adotadas pelos não videntes, são baseadas no senso particular de orientação e de direção, que podem ser aprimorados através de treinamento e do uso de equipamentos adequados, mapas táteis para lugares muito complexos por exemplo. Cada termo, tecnologia e instrumento estudado encontram-se vinculados a outros em maior ou menor grau, o que para a locomoção de um deficiente visual, tanto em ambientes familiares como em ambientes desconhecidos, se fazem igualmente úteis e necessários à maior independência deste indivíduo.

\section{OBJETIVO GERAL E OBJETIVOS ESPECÍFICOS}

O objetivo geral da pesquisa consistiu no levantamento das referências bibliográficas da área de acessibilidade para deficientes visuais, e na atualização de informações sobre as tecnologias assistivas existentes e em desenvolvimento. Em ambos os tópicos foram pesquisados produções brasileiras e internacionais.

O objetivo específico foi investigar como instrumentos de auxílio à mobilidade contribuem para a orientação espacial urbana de indivíduos com deficiência visual. Foram investigadas as premissas e técnicas sobre segurança no percurso e mobilidade urbana, e como instrumentos de auxílio representativos do espaço da cidade (maquetes e mapas) podem contribuir para o aprendizado, trabalhando os conceitos de inclusão espacial e percepção ambiental. 


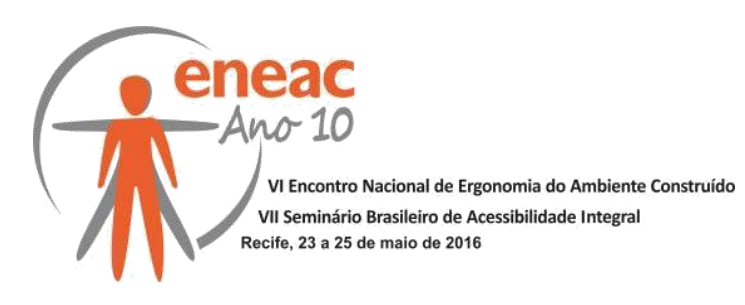

\section{METODOLOGIA}

A primeira etapa consistiu no levantamento e estudo da bibliografia, contato com instituição de ensino de mobilidade para realização do estudo de caso e desenho da metodologia a ser aplicada no estudo de caso. A segunda etapa contemplou a realização do estudo de caso (visitas, entrevistas, aula experimental e roteiro acompanhado), análise e discussão dos dados à luz da bibliografia e a elaboração da conclusão.

O estudo de caso foi baseado no mapeamento sensorial, metodologia utilizada na pesquisa com o mapa tátil sonoro do Ciclo Básico da Unicamp (d'ABREU \& BERNARDI, 2011) e adaptada da metodologia do mapeamento visual descrita por Rheingantz (2009) e do mapa sensorial descrito por Ventorini (2009), porém direcionada a pessoas com deficiência visual. O mapeamento visual permite identificar os atributos do espaço urbano e construído através da percepção do usuário em relação ao ambiente. No mapeamento sensorial é possível identificar estes mesmos atributos, porém, utilizando-se de estímulos que são apreendidos pelos sensores táteis e auditivos do corpo humano.

Rheingantz (2009) aponta diversos métodos de avalização pós-ocupação que se mostraram úteis à pesquisa de campo realizada na etapa final desta pesquisa. Dentre os métodos, os que melhor se adaptaram ao intuito da pesquisa foram os métodos da Entrevista, Aplicação de Questionários e a Observação Incorporada.

A entrevista resulta em um conjunto de informações sobre os sentimentos, crenças, pensamentos e expectativas das pessoas. A aplicação de questionários é utilizada quando se necessita descobrir regularidades entre grupos de pessoas. E a observação incorporada permite que o observador assuma uma postura menos distanciada, passando a ter consciência da subjetividade das emoções e reações que são vivenciadas com os usuários no ambiente, que também devem ser considerados como sujeitos ou protagonistas da experiência.

\subsection{Materiais}

Para o estudo de caso, foram selecionadas instituições que tem como objetivo o aprendizado de mobilidade urbana de pessoas com deficiência visual. A escolha destes locais teve como critérios e condicionantes os seguintes fatores: 0 acesso e a disponibilidade de visita (permissões por parte da gerência destes locais); o acesso prévio ao material gráfico da construção e entorno (plantas, detalhes técnicos, material fotográfico, memoriais) e a segurança oferecida pelo local. Foram utilizados instrumentos de observação com referência na metodologia do mapeamento visual, realizado pela pesquisadora e instrumentos para o mapeamento sensorial. Foram aplicadas entrevistas com administradores e professores da instituição visitada e desenvolvidos questionários que foram aplicados aos alunos com deficiência visual que realizam atividades periódicas na instituição selecionada.

Para o estudo de caso, foi contactada a Associação dos Deficientes Visuais de Salto 1 (ADEVISA), onde o método descrito por Rheingantz foi aplicado com o intuito de compreender os atributos do ambiente construído através da percepção de indivíduos com deficiência visual.

\footnotetext{
1 Dados da Instituição: ADEVISA - Associação dos Deficientes Visuais de Salto. Entidade civil, de direito privado, sem fins lucrativos, fundada em 05/12/2000.Rua Floriano Peixoto, 1596 (Entrada pela Rua Regente Feijó) - Vila Nova - Salto/SP. Telefone: (11) 4021-5053Site: www.adevisa.com.br
} 


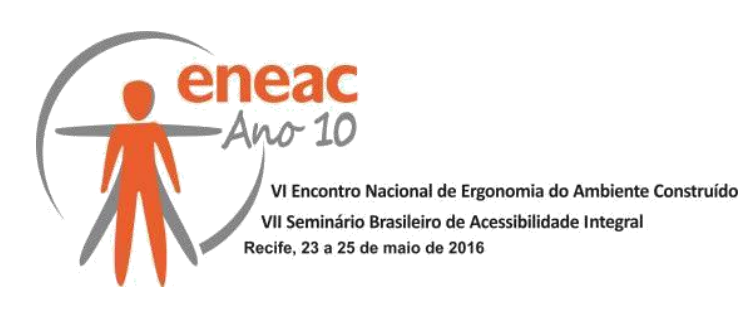

a) Roteiro de visitas:

$O$ roteiro de visitas e atividades foi elaborado com base na pesquisa bibliográfica e em entrevistas com os coordenadores técnicos da instituição definida para a realização do estudo, para então serem realizadas as observações e as atividades envolvendo os alunos voluntários, como segue abaixo:

1ำ visita: entrevista com a coordenação;

$2^{\underline{a}}$ visita: conversa com a coordenação para definição das atividades;

3 ${ }^{\text {a }}$ visita: atividade interna (aula experimental de reconhecimento de um sanitário) e entrevista com os alunos;

Demais visitas: atividades externas - realização do percurso urbano e da última entrevista com os alunos, em dias diferentes (de acordo com a disponibilidade da instituição e dos voluntários).

a) Questionários:

Foram elaborados antes e durante o estudo de caso, e aplicados conforme o andamento da pesquisa, direcionados aos coordenadores da instituição, aos técnicos de mobilidade e aos deficientes visuais.

O primeiro questionário foi aplicado em forma de entrevista à Coordenadora Pedagógica da ADEVISA e Técnica de Orientação e Mobilidade. As perguntas tiveram como foco os serviços oferecidos, o público alvo e a metodologia de ensino de mobilidade, e as respostas obtidas nortearam as entrevistas e atividades que se seguiram, com a finalidade de obter 0 máximo de informações pertinentes ao tema desta pesquisa.

O segundo questionário foi aplicado aos alunos, junto ao técnico de orientação e mobilidade, em diferentes ocasiões. Com este questionário foi possível detectar desde aspectos mais gerais, até as experiências mais pessoais de cada individuo em relação à mobilidade urbana. Outro dado relevante constituiu na apresentação de dificuldades e facilidades em comum. Neste questionário estão contidas as perguntas gerais e sobre o percurso realizado sem e com interferência da pesquisadora, segundo a Observação Incorporada definida por Rheingantz (2009).

b) Percurso definido:

O percurso para a realização da pesquisa (Figura 1) foi estabelecido em conjunto com os profissionais da instituição, e envolveu atividades como atravessar ruas pouco e muito movimentadas, localizar-se na calçada, passar por obstáculos no chão e na altura dos olhos, andar sob sol e sob sombra, e deslocar-se numa rua e numa praça. Percursos realizados:

Percurso de Ida - Saímos da instituição Adevisa e caminhamos pela Rua Regente Feijó, até a praça localizada na Rua Duque de Caxias, atravessando a Rua Floriano Peixoto;

Percurso de Volta - Iniciou por dentro da praça, atravessamos a Rua Regente Feijó e voltamos para a instituição pela outra calçada, atravessando as Ruas Floriano Peixoto e Regente Feijó nos seus trechos mais movimentados. 


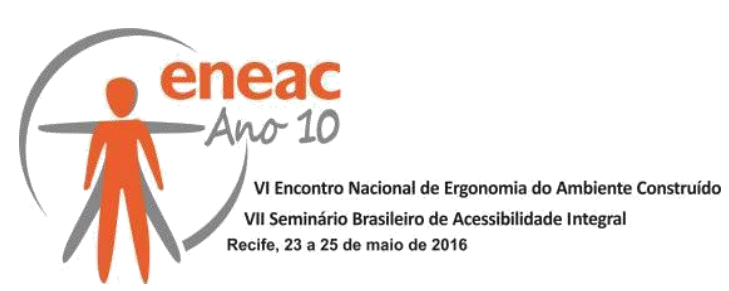

FIGURA 1 - Infográfico do percurso realizado no estudo de caso.

\section{Legenda: \\ 1 - Adevisa \\ 2 - Praça

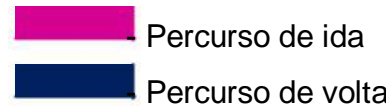 \\ - trafego intenso de automóveis e ônibus \\ - trafego intenso de caminhões}

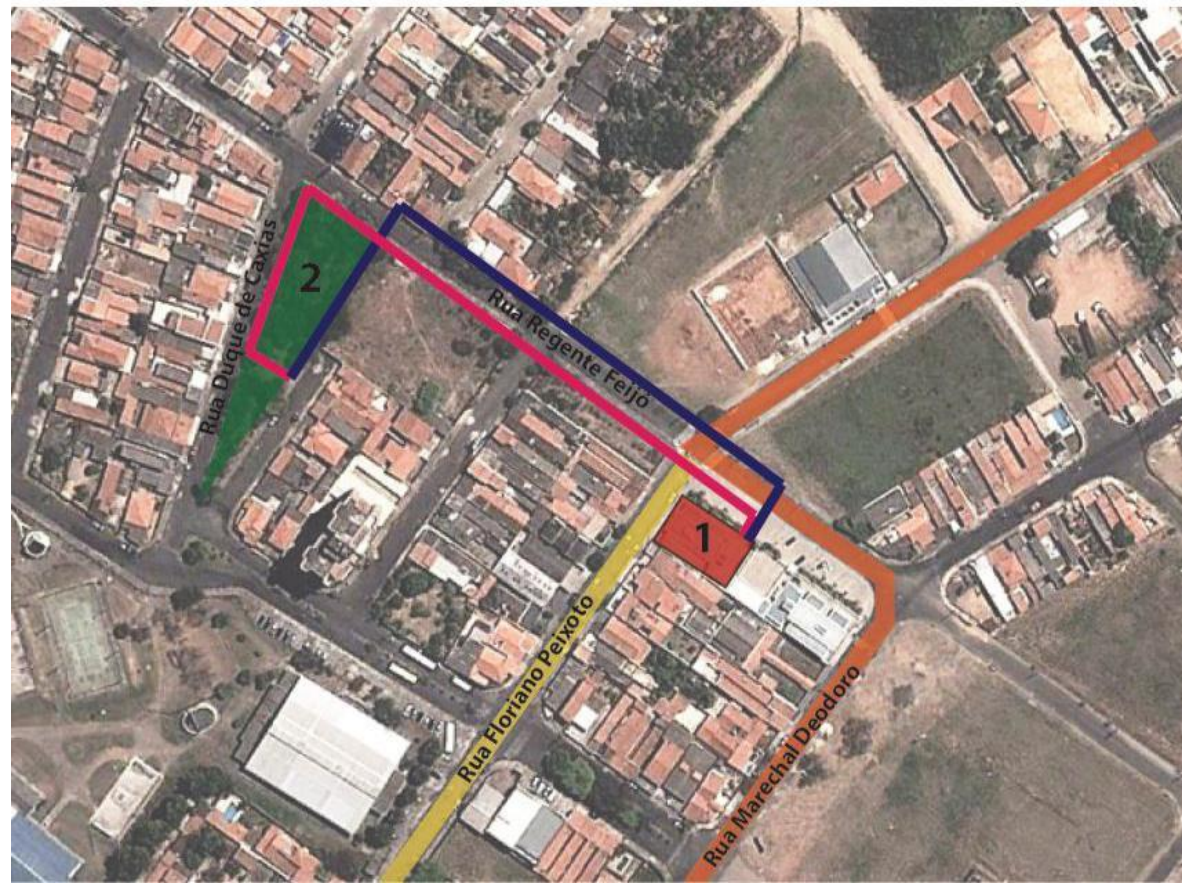

Fonte: Foto aérea do Google Earth, inclusão das informações gráficas pela autora.

\section{RESULTADOS}

$1^{\underline{a}}$ visita e $2^{\underline{a}}$ visitas: entrevista com a coordenação e definição das atividades;

Nestas visitas foi aplicado um questionário à coordenação, com o intuito de saber exatamente quais atividades a instituição oferece, e como a pesquisa poderia ser realizada junto aos alunos, podendo até colaborar com as atividades de rotina da Adevisa (Tabela 1).

Tabela 1:

\begin{tabular}{|l|l|}
\hline \multicolumn{2}{|l|}{ Sobre o trabalho realizado pela ADEVISA: } \\
\hline$\underline{\text { Publico alvo: }}$ & $\begin{array}{l}\text { Pessoas com deficiência visual (baixa visão ou cegueira) de todas as } \\
\text { idades, seus cuidadores e familiares. }\end{array}$ \\
\hline$\underline{\text { Serviços: }}$ & $\begin{array}{l}\text { Alfabetização e aulas de Braile, terapias e oficinas, acompanhamento } \\
\text { psicológico e social, além das aulas de orientação e mobilidade. }\end{array}$ \\
\hline$\underline{\text { Frequência dos }}$ & $\begin{array}{l}\text { Os alunos comparecem uma vez por semana para as terapias e demais } \\
\text { acompanhamentos, e até três vezes por semana para as aulas de } \\
\text { informática e outras oficinas não regulares. }\end{array}$ \\
\hline $\begin{array}{l}\text { Profissionais } \\
\text { envolvidos: }\end{array}$ & $\begin{array}{l}\text { Assistente social, pedagogos, professores (braile, educação física, } \\
\text { informática e música), psicólogos e terapeutas ocupacionais. }\end{array}$ \\
\hline
\end{tabular}




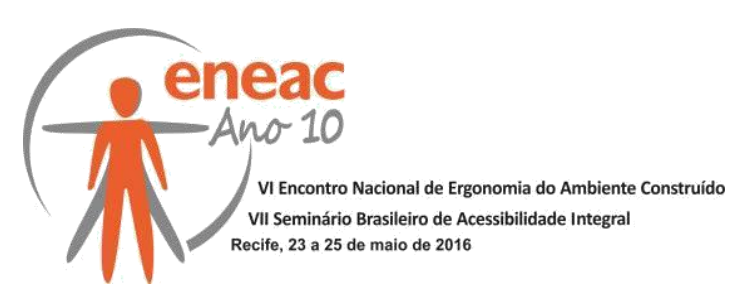

\begin{tabular}{|l|l|}
\hline Objetivos: & $\begin{array}{l}\text { Promover a autonomia e a melhoria da qualidade de vida das pessoas } \\
\text { com deficiência, seus cuidadores e familiares; desenvolver ações que } \\
\text { previnam situações de violações de direitos e intensificação da } \\
\text { dependência; promover a orientação á rede de serviços referente á } \\
\text { inclusão social. }\end{array}$ \\
\hline$\underline{\text { Atendimento de }}$ & $\begin{array}{l}\text { Individualizado. O tempo de duração depende de cada aluno, podendo } \\
\text { varientação e de seis meses a dois anos, ou até mais, para que a pessoa se } \\
\text { torne independente. }\end{array}$ \\
\hline$\underline{\text { mobilidade (OM): }}$ & $\begin{array}{l}\text { Nomo inicio são feitas atividades e orientações dentro do espaço da escola, } \\
\text { depois o treinamento ocorre na casa do aluno para que ele aprenda a } \\
\text { realizar tarefas cotidianas, e então começam os treinamentos em } \\
\text { ambiente urbano. }\end{array}$ \\
\hline$\underline{\underline{\text { Quais os instrumentos }}}$ & $\begin{array}{l}\text { As crianças começam utilizando objetos e brinquedos (utilizados com pré- } \\
\text { bengala), os jovens e adultos fazem uso da bengala branca, de ponta } \\
\text { e equipamentos } \\
\text { seca ou roller, de acordo com as afinidades pessoais. Mapas táteis e } \\
\text { outros equipamentizados eletrônicos não são utilizados devido á dificuldade } \\
\text { de obtenção dos mesmos, de cunho principalmente financeiro. }\end{array}$ \\
\hline
\end{tabular}

$3^{\text {a }}$ visita: atividade interna (aula experimental de reconhecimento de um sanitário) e entrevista com os alunos;

Nesta visita foi realizada uma atividade interna, contando com a coordenadora, com o professor de mobilidade, e quatro alunos voluntários (Tabela 2), com diferentes tipos e graus de deficiência visual, bem como diferentes graus de independência no que se refere à mobilidade urbana.

\section{Tabela 2:}

\section{Sobre o perfil dos voluntários:}

Voluntário 1: Homem, aposentado, 59 anos, cegueira adquirida por doença ocular há 6 anos (consegue identificar luminosidade), utiliza a bengala branca de ponta seca e frequenta a instituição há 4 anos. Desloca-se em meio urbano com frequência, até mesmo sozinho quando o percurso já é conhecido.

Voluntário 2: Mulher, aposentada (LOA), 46 anos, baixa visão congênita que se agravou com o tempo (consegue identificar luminosidade), utiliza a bengala roller e guia vidente, frequenta a instituição há cinco anos. Desloca-se em meio urbano com frequência, mas somente acompanhada da guia vidente (irmã da voluntária)

Voluntário 3: Homem, 38 anos, baixa visão adquirida a menos de um ano (doença que provoca a cegueira), frequenta a entidade há dois meses, e só se desloca com guia vidente pois ainda está se preparando para utilizar a bengala branca, desde que perdeu a visão deslocou-se muito pouco em ambiente urbano.

Voluntário 4: Mulher, 40 anos, cegueira congênita, utiliza a bengala branca e guia (o próprio marido, que também é cego, e o filho, que é vidente), frequenta a entidade há 10 anos e só se desloca em meio urbano acompanhada do marido ou do filho.

$\mathrm{Na}$ mesma ocasião foram feitas as entrevistas mais gerais, para conhecer quais são as situações vivenciadas por eles no meio urbano, quais as dificuldades encontradas, quais as facilidades que realmente fazem a diferença, e quais as ideias e propostas que eles já possuíam para um melhor deslocamento urbano. (Tabela 3). 


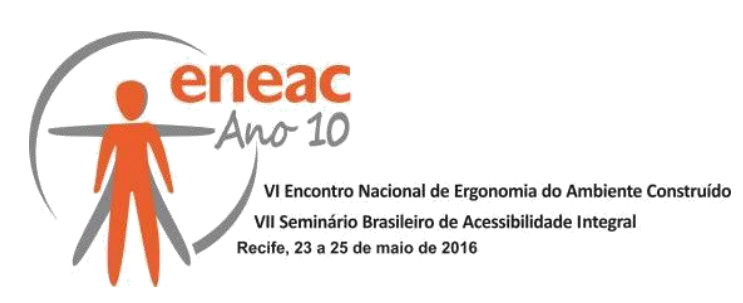

Tabela 3:

\begin{tabular}{|c|c|}
\hline \multicolumn{2}{|r|}{ Sobre as situações enfrentadas em ambiente urbano } \\
\hline Voluntário 1: & $\begin{array}{l}\text { Desloca-se bem na cidade, e diz usar a bengala branca para sinalizar a } \\
\text { deficiência e com isso conseguir o auxilio das pessoas no seu trajeto e nas } \\
\text { tarefas que precisa realizar. }\end{array}$ \\
\hline Voluntário 2: & $\begin{array}{l}\text { Utiliza muito o transporte público municipal, e relatou muitos problemas em } \\
\text { relação à falta de educação das pessoas para com os deficientes. }\end{array}$ \\
\hline Voluntário 3: & Não teve nada a declarar. \\
\hline Voluntário 4: & $\begin{array}{l}\text { Relatou apenas problemas relacionados á obstáculos nos percursos, como } \\
\text { dificuldade em atravessar as ruas e calçadas esburacadas. }\end{array}$ \\
\hline
\end{tabular}

Além disso, nesta mesma data a pesquisadora também participou com os alunos de uma atividade interna (seguindo o calendário das aulas de Orientação e Mobilidade), com os olhos vendados foi feito o reconhecimento de um banheiro público. Dessa atividade pode-se apreender como proceder na orientação de um deficiente visual, através dos comentários e alertas que os instrutores usaram, enriquecendo a Observação Incorporada que ainda seria realizada.

No mês seguinte houve algumas mudanças na coordenação da instituição, o que prejudicou as atividades in loco, minimizando o tempo disponível para a realização do estudo de caso, que consequentemente ficou agendado para o mês seguinte, quando foram realizados os dois estudos de caso (6.1 - tabelas 4 e 5), os outros dois voluntários que iriam participar da pesquisa faltaram á aula na data marcada, e não foi possível reagendar a atividade antes do recesso da instituição.

\subsection{Descrição dos Resultados - Tabelas e Imagens}

As visitas à instituição ocorreram entre os meses de março e junho de 2013 , de acordo com a disponibilidade dos alunos e dos professores de mobilidade.

O estudo de caso baseou-se na realização de um pequeno percurso, inicialmente, seguindo à risca a proposta da Observação Incorporada de Rheingantz (2009), onde o autor explica que é preciso realizar o percurso uma primeira vez sem que haja a interferência do pesquisador, e numa segunda ocasião seja realizado o mesmo percurso, aí então com a interferência do pesquisador.

Como o tempo disponível para a realização do estudo encurtou devido à mudanças na coordenação da entidade, o percurso foi realizado apenas uma vez com cada aluno, sendo que na ida, a pesquisadora em nada interferia, e na volta acontecia a interferência.

Os resultados do estudo de caso, bem como as imagens e fotos feitas durante a realização da atividade seguem descritas nas tabelas 4 e 5 a seguir. 


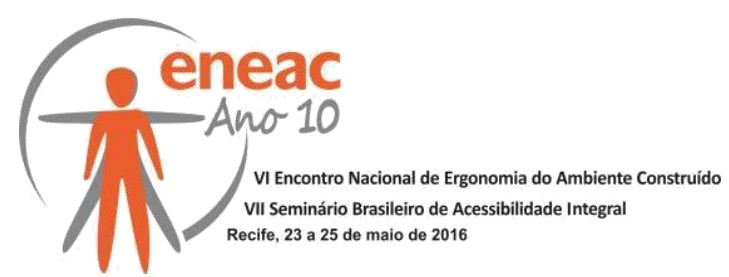

Tabela 4:

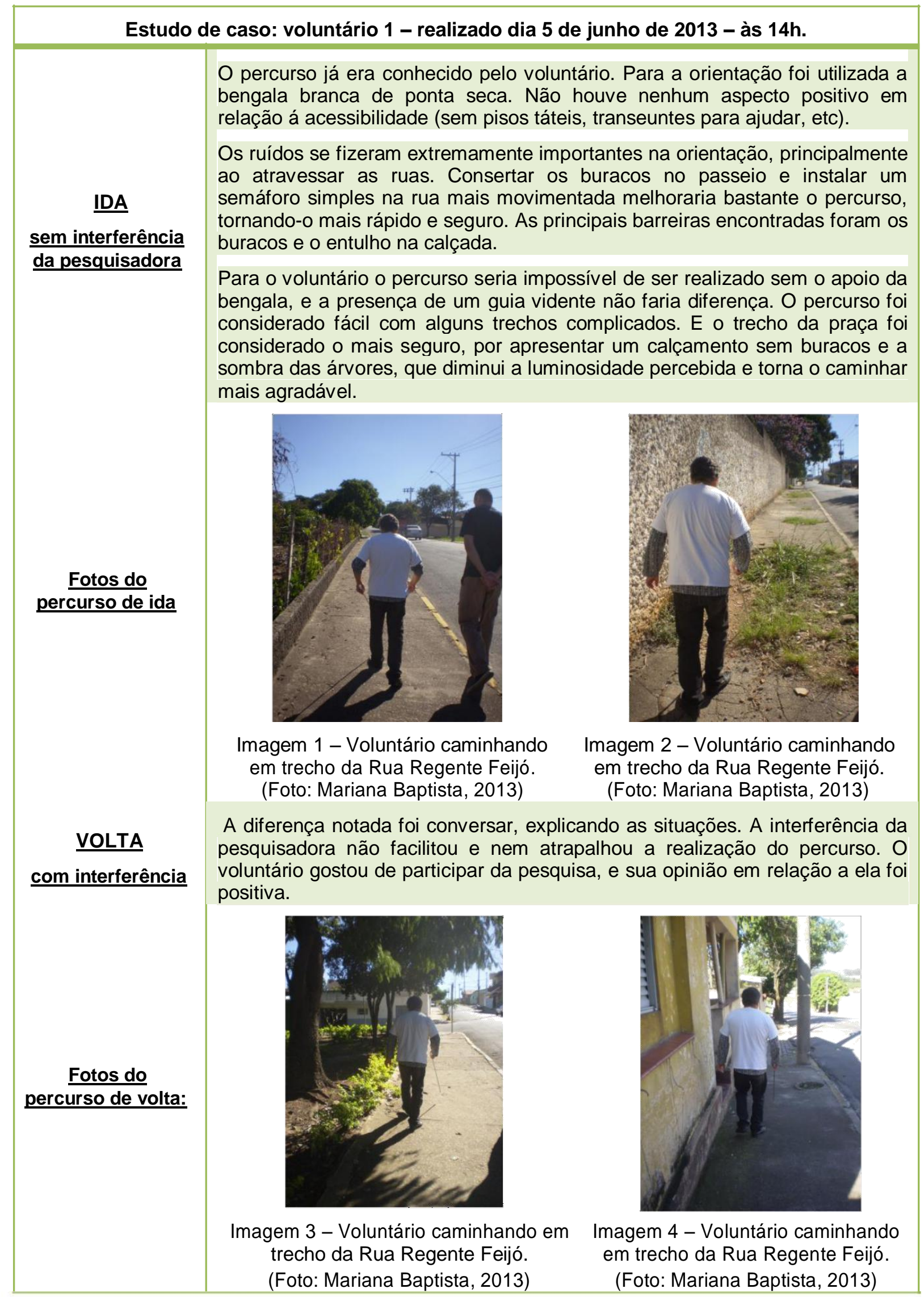




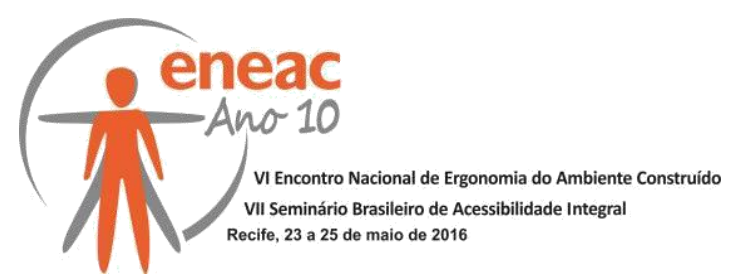

Tabela 5

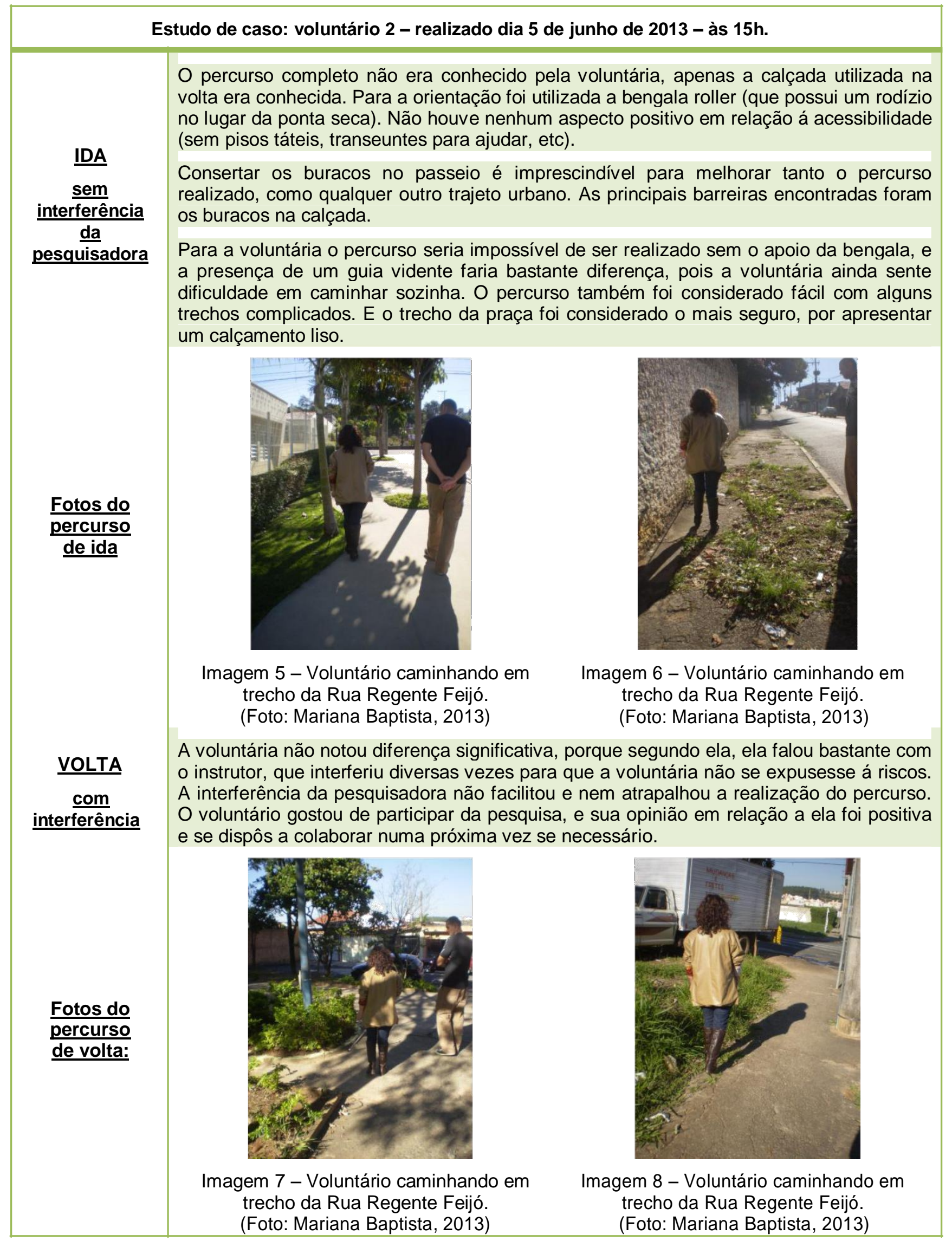




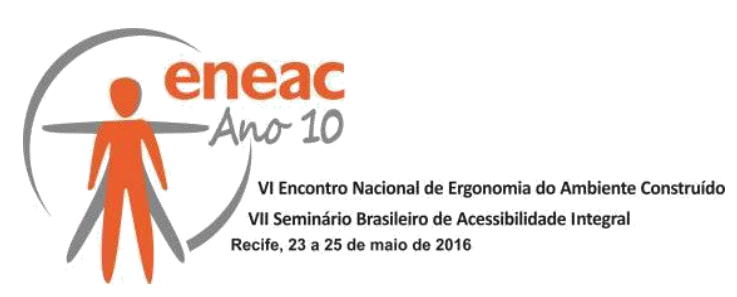

Inicialmente o estudo de caso contava com a participação de quatro voluntários, porém isso não foi possível devido à indisponibilidade de tempo da entidade e dos alunos, fazendo com que a pesquisa contasse apenas com os voluntários de número 1 e 2 . Certamente se a pesquisa tivesse sido realizada com a presença dos 4 voluntários previamente definidos, os resultados seriam enriquecidos com diferentes discussões e perspectivas de uso dos espaços percorridos.

\section{CONCLUSÕES}

Ao final desta pesquisa, foram obtidas informações valiosas ao aprendizado da mobilidade urbana, contribuindo para a inclusão sócio-espacial e percepção do ambiente pelos deficientes visuais, coletando e analisando dados úteis ao desenvolvimento de novos equipamentos e de novos cuidados arquitetônicos, ampliando a pesquisa sobre orientação espacial e mobilidade urbana, como segue abaixo:

- Bengala branca de ponta seca: mostrou-se ideal para espaços ainda não conhecidos e que ofereçam obstáculos como grama, pois a ponta seca ao bater nos materiais indica ao deficiente que tipo de solo ele está pisando através das vibrações e sons produzidos, além de não enroscar na grama e demais obstáculos soltos, como pedregulhos.

- Bengala roller: funciona muito bem em espaços sem obstáculos e por ser de rolamento e não de varredura é capaz de identificar o 'intervalo' dos espaços que a bengala de ponta seca não identifica.

Guia vidente: torna-se desnecessário se o deficiente puder contar com a bengala e com o respeito de transeuntes e motoristas, melhor ainda se houverem pisos táteis e semáforos, mesmo que simples.

- Calçadas: com buracos, entulhos, e ocupadas indevidamente representam verdadeiro atraso no deslocamento dos deficientes visuais. Obrigando-os a alterar rotas e levar mais tempo para analisar o solo e decidir onde pisar.

- Muros: são a referência de segurança do deficiente visual, guiando-se pelo muro, o deficiente consegue se sentir seguro em relação á movimentação dos carros.

- Guias rebaixadas: oferecem risco quando não indicam o inicio do leito carroçável, o deficiente percebe que chegou a uma esquina por sentir que a circulação de ar aumentou, e por perceber com a bengala que as construções (muros e casas) 'acabaram' no entanto sem a indicação de piso tátil na guia rebaixada ele não consegue saber onde exatamente a calçada termina.

- Piso tátil: muito útil, mas deve-se ter o cuidado de instalá-lo sobre um piso com superfícies de texturas diferentes. Um piso tátil instalado sobre um piso com ranhuras grosseiras ou sobre pavimento quebrado, oferece risco ao invés de segurança.

Com esta experiência foi possível avaliar como os instrumentos de apoio e os estímulos gerados pelo ambiente são apreendidos pelos usuários e qual a importância de tais instrumentos para a percepção em relação ao ambiente, utilizando parâmetros de localização, apropriação, demarcação de território, crítica às situações existentes e identificação de barreiras existentes. O conjunto das três ferramentas utilizadas - Entrevista, 


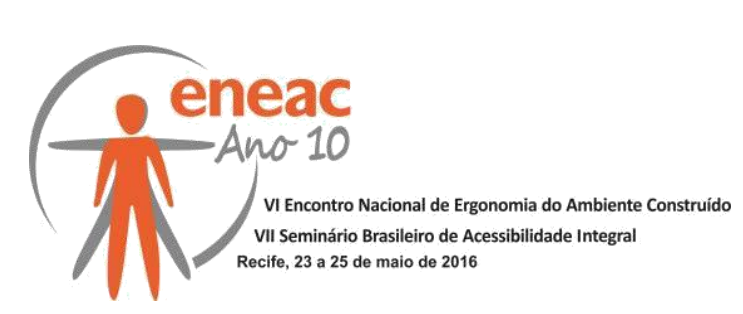

Aplicação de Questionários e a Observação Incorporada - resultou em informações sobre os sentimentos, pensamentos e expectativas dos deficientes visuais em relação à sua mobilidade e às técnicas assistivas das quais fazem uso.

\section{REFERÊNCIAS}

D'ABREU, J. V. V.; BERNARDI, N. Orientação Espacial no Campus da Unicamp: Desenvolvimento de um mapa de uso tátil e sonoro como ferramenta de auxílio ao percurso do usuário Relatório de Pesquisa.Processo Fapesp: 2009/00216-8, 2011.

DISCHINGER, M.; MATTOS, M.L.; BRANDÃO, M.M.; ELY, H.M.B. Orientar-se em campi universitário no Brasil: condição essencial para inclusão. In Ponto de Vista, Florianópolis, n.10, p.39-64, 2008.

IBGE. Censo Demográfico de 2010. Disponivel em http://www.ibge.gov.br/home/estatistica/populacao/censo2010/default.shtm. Acesso em abril/2012

LEI No.10.098, de 19 de dezembro de 2000. Estabelece normas gerais e critérios básicos para a promoção da acessibilidade das pessoas portadoras de deficiência ou com mobilidade reduzida, e dá outras providências. Presidência da República, Casa Civil, Subchefia para assuntos Juridicos. Disponivel em: http://www.presidenciadarepublica.gov.br/ccivil 03/LEIS)L10098.htm Acesso em 2012.

RHEINGANTZ, P.A.; AZEVEDO, G.A.; BRASILEIRO,A; ALCÂNTARA,D.D.; QUEIROZ, M. Observando a qualidade do lugar: procedimentos para a avaliação pós-ocupação, ProArq. Edição eletrônica. Rio de Janeiro: Universidade Federal do Rio de Janeiro, Faculdade de Arquitetura e Urbanismo, Pós-Graduação em Arquitetura. Disponível em www.fau.ufrj.br/prolugar, 2009.

SANTOS, A. O cego, o espaço, o corpo e o movimento: uma questão de orientação e mobilidade. Instituto Benjamin Constant, Rio de Janeiro, 1999, disponível em: http://www.ibc.gov.br/?itemid=106\#more, acessado em janeiro de 2013.

STORY, M. F. Principles of Universal Design in PREISER, W. F. E.; OSTROFF, E (ed). Universal Design Handbook. New York: Mc-Graw-Hill, 2001.

VENTORINI (2009) in ULBRICHT, V.R.; QUEVEDO, S.R.P.; FLORES, A.B.; MACEDO, C.M.S.; GONÇALVES, M.M.; AMARAL, M.; VANZIN, T.; VILLAROUCO, V. Os deficientes visuais e a aprendizagem da representação espacial. In XX Simposio Nacional de Geometria Descritiva e Desenho Técnico, Rio de Janeiro, 2011, p.6. Disponível em http://www.graphica.org.br/CD/PDFs/EDUCA/EDUCA56.pdf acessado em janeiro de 2013. 